\title{
Relationship of Serum Lipid Profiles and Serotonin with Major Depression: A Matched Case-Control Study
}

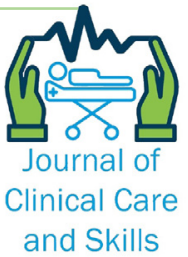

and Skills

\section{ARTICLE INFO}

\section{Article Type}

Original Research

\section{Authors}

Hashemi Mohammad-Abad N. ${ }^{1} M D$,

Hoseiniyan L. ${ }^{1} M D$

Malekzadeh $\mathrm{J}{ }^{* 2} \mathrm{PhD}$

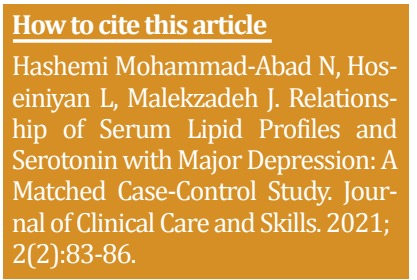

${ }^{1}$ Department of Psychiatry, Faculty of Medicine, Yasuj University of Medical Sciences, Yasuj, Iran ${ }^{2}$ Social Determinants of Health Research Center, Yasuj University of Medical Sciences, Yasuj, Iran

\section{*Correspondence}

Address: School of Health, Yasuj University of Medical Sciences, Yasuj, Iran. Postal Code: 7591875114

Phone: +98 (74) 33223505

Fax: +98 (74) 33226715

malekjmd@yahoo.com

\section{Article History}

Received: January 29, 2020

Accepted: April 05, 2021

ePublished: June 20, 2021

\section{A B S T R A C T}

Aims Depression is a common mental disorder. This study aimed to evaluate the relationship between serum lipid profiles and serum serotonin with depressive disorder.

Materials \& Methods This study was carried out on patients with depressive disorders referred to Shahid Mofteh Clinic in Yasuj, Iran, in 2016. The total serum cholesterol, LDL-C, HDL-C, and serum serotonin of 45 patients with the depressive disorder as a case group and 45 normal people without depressive disorder as a control group was measured. Age, sex, weight, and height were matched in both groups. Diagnosis of depression was conducted using both the Beck and Hamilton depression rating scale, followed by an interview by a psychiatrist. Data were analyzed using the SPSS 19 software by sample t-test and the chisquare test.

Findings The LDL-C serum concentrations of the case group was higher than the control group (121.1 \pm 30.9 vs107.9 \pm 36.9 ; $p=0.07)$; moreover, the HDL-C serum of the case group was significantly lower than the control group $(52.6 \pm 11.9$ vs. $34.4 \pm 9 ; \mathrm{p}<0.0001)$. The Serum serotonin of the case group was higher than the control group, but this difference was not statistically significant ( $455.9 \pm 393$ vs. $418.1 \pm 224.4 ; \mathrm{p}=0.58)$. The total cholesterol and Triglyceride of the case group were higher than the control group, but these differences were not statistically significant (178 \pm 37.8 vs. $191.2 \pm 47$ and $127.4 \pm 56.2$ vs. $148.5 \pm 88.4$ respectively; $\mathrm{p}=0.14$ ).

Conclusion The serum HDL-C concentration of depressed patients is lower than normal people, and the serum LDL-C concentration of depressed patients is higher than normal people.

\section{Keywords Depression; Cholesterol; Serotonin; LDL-C; HDL-C}

\section{T A T I O N L INKS}

[1] Epidemiology of depression ... [2] The epidemiology of major depressive disorder: Results ... [3] Prevalence and distribution of major depressive ... [4] Cholesterol and mental ... [5] Association of low serum total cholesterol ... [6] Kaplan and Sadock's synopsis of psychiatry... [7] Serum leptin and cholesterol values in ... [8] LDL cholesterol relates to depression ... [9] High cholesterol, triglycerides, and body ... [10] Low cholesterol is associated with ... [11] HDL cholesterol and the risk of depression ... [12] Associations between cholesterol and fatty acid ... [13] Association between total serum cholesterol ... [14] Are serum cholesterol levels associated with ... [15] Association of serum lipid profiles with ... [16] No evidence for an association ... [17] Low levels of cholesterol and the cholesterol ... [18] Relation of serum cholesterol, lipid ... [19] Relationship between serum cholesterol ... [20] Chronic cholesterol depletion using statin ... [21] Sample size tables for clinical ... [22] Psychometric properties of a Persian ... [23] Validity and reliability of the depression in old ... [24] Psychometric properties of the Beck depression ... [25] Psychometrics Characteristic of Beck Depression ... [26] The Hamilton rating scale for ... [27] Application of the Beck Depression ... [28] Attribution style in patients with anxiety ... [29] Serum lipids: New biological markers ... [30] Lower HDL-cholesterol, a known marker ... [31] Serum lipid concentrations in patients ... [32] Low serum cholesterol in suicide ... [33] Association of lipid profile with depressive ... 
Relationship of Serum Lipid Profiles and Serotonin ... Introduction

Depression is a common mental disorder characterized by depressed mood, anhedonia, anorexia, insomnia, difficulty concentrating, lethargy, and suicidal considerations. The prevalence of depression is $10-15 \%$ in the general population and higher among women than men [1-3]. The definite etiology of depression is unknown, but biological, hormonal, environmental, genetic, and psychosocial factors have been reported. There are certain shreds of evidence about the relation between serum lipids and depressive disorder, aggression, suicide, and some other psychiatric disorders [4-8].

Various studies have reported that high serum cholesterol and/or triglyceride, high LDL-C, and/or low HDL-C are related to depression and suicidal attempts [8-12]; however, other studies showed a relation between low serum cholesterol and depression [10-13], higher serum LDL-C and lower depression [14] or did not show any significant association between lipid profiles and depressive disorders [15-17]. Serum serotonin levels were significantly lower in patients with depression committing a recent suicidal attempt than those who did not [18]. In one report, Terao et al. showed that the serum cholesterol levels might be positively associated with serotonergic receptor function and low serum levels of serotonin [19]. It appears that may be a relationship between serum cholesterol and serotonin action and also psychiatric disorders, especially depressive disorders ${ }^{[20]}$.

According to the controversies on the relationship between cholesterol profiles and depression disorders, This study aimed to compare the total serum cholesterol levels, triglyceride, serum HDL-C, LDL-C, and serotonin in a group of newly-referred depressed patients with the matched healthy controls.

\section{Materials and Methods}

This study was carried out on patients with depressive disorders referred to Shahid Mofteh Clinic in Yasuj, Iran, in 2016. Forty-five samples in each group were estimated considering the $95 \%$ test confidence interval, $90 \%$ test power, and about $30 \mathrm{mg} / \mathrm{dL}$ variance of total serum cholesterol according to the study by Deisenhammer et al. [16], to test the assumption of $15 \mathrm{mg} / \mathrm{dL}$ different serum cholesterol concentrations between the two groups [21]. The sampling method was convenient. The inclusion criteria for cases were being newly diagnosed depressive patients and not receiving any medical treatment up to diagnosis. The patients who previously received any kind of antidepressant and hypolipidemic agents or were on a diet and those who were alcohol abusers, substance abusers, and who had cancer or any somatic disease were not included in the study. Also, Women were excluded if they were pregnant or breastfeeding their child.
A locally validated Beck depression inventory test was used to identify depressed candidates [22,23]. For the Beck depression inventory, a score $>10$ was considered as depressed, within 10-19 regarded as mild, 20-29 as moderate, 30-39 as partially severe, and $>40$ as severe depression $[24,25]$. A score of $0-7$ was generally accepted within the normal range in the Hamilton rating scale, while a score of 20 or higher (indicating at least moderate severity) was required for entry into the study [26]. The validity and reliability of the beck test are approved by Rahimi et al. [27]. In this study, the reliability and correlation coefficients of 0.55 and 0.83 were obtained from testretest and Cronbach's alpha methods, and Gharaie et al. reported the reliability coefficient of the Hamilton Stress Rating Scale with the Hilton Anxiety Rating Scale using the retest method of 0.85 and 0.89 [28]. The total serum cholesterol, LDL, and HDL cholesterol were measured by Auto-Analyzer, model 912 (Hitachi, Japan), and the serum serotonin by ELISA method using ELISYS-UNO (Human co, Germany).

The ethics committee and vice chancellor for research at Yasuj University of Medical Sciences approved the study. Patients were informed about this research, and written informed consent was obtained from participants or their legal guardians. The controls were matched with patients' age, sex, weight, height, and body mass index (BMI) were filled in a datasheet for all cases and controls. Patients filled the Beck depression rating scale and Hamilton rating scale; moreover, a psychiatrist visited them to determine not having a psychological problem. Forty-five newly diagnosed major depression patients diagnosed through evaluation by the Beck depression rating scale (score $>39$ ) and/or Hamilton rating scale (score $>19$ ) and psychiatrist interview were selected as cases. Forty-five healthy people were also selected as their control. Both the case and control groups were referred to the Laboratory of Imam Sajad Hospital of Yasuj to measure their total serum cholesterol, LDL-C, HDL-C, and serotonin.

Data were analyzed using the SPSS 19 software. The continuous data were tested for normality distribution, and they did not show significant distribution from normality, so the parametric independent sample t-test was used to compare two groups' means. The Qualitative variables were analyzed using the chi-square test.

\section{Findings}

There were 18 men and 72 women in both groups, 9 (20\%) men and $36(80 \%)$ women in the case group, and $9(20 \%)$ men and $36(80 \%)$ women in the control group.

There was no significant difference between the two groups regarding the basic demographic data, including age, gender, weight, height, and BMI (Table 1). 
Table 1) The mean \pm SD of age, weight, height, and BMI of case and control groups

\begin{tabular}{llll}
\hline Variable & Case & Control & p-value \\
\hline Age & $35.2 \pm 11.4$ & $35.6 \pm 9.7$ & 0.8 \\
Weight & $64.2 \pm 12.2$ & $66.7 \pm 9.8$ & 0.3 \\
Height & $163.3 \pm 8.3$ & $161.7 \pm 5.9$ & 0.3 \\
BMI & $24.1 \pm 4.9$ & $25.4 \pm 3.3$ & 0.16 \\
\hline
\end{tabular}

Although there was a difference between the two groups in terms of total cholesterol, TG, and serotonin, these differences were not significant. The LDL-C concentration of the case group was more than the control group; similarly, the HDL-C concentration of the case group was lower than the control group; these differences were significant (Table 2).

Table 2) Mean \pm SD of serum lipids and serotonin of case and control groups

\begin{tabular}{llll}
\hline Index & Case & Control & p-value \\
\hline HDL $(\mathrm{mg} / \mathrm{dl})$ & $34.4 \pm 9.0$ & $52.6 \pm 11.9 .0$ & 0.0001 \\
LDL $(\mathrm{mg} / \mathrm{dl})$ & $121.1 \pm 30.9$ & $109.7 \pm 36.9$ & 0.07 \\
Total cholesterol $(\mathrm{mg} / \mathrm{dl})$ & $178 \pm 37.8$ & $191.2 \pm 47.0$ & 0.14 \\
TG $(\mathrm{mg} / \mathrm{dl})$ & $127.4 \pm 56.2$ & $148.5 \pm 88.4$ & 0.18 \\
Serum serotonin $(\mu \mathrm{g} / \mathrm{dl})$ & $455.9 \pm 393$ & $418.1 \pm 224.4$ & 0.58 \\
\hline
\end{tabular}

\section{Discussion}

The present study's findings indicated that the serum HDL-C concentration of depressed patients was significantly lower than the control group. However, the total serum cholesterol, LDL, and triglycerides differences were not statistically significant between the two groups. Tedders et al. reported a U-shaped relation between LDL-C and depression, showing that both high and low serum LDL-C may be related to depression [10], while other studies reported a lower serum LDL-C in depression [29]. On the other hand, other studies did not find any significant relation between the serum LDL-C and depression in different human subjects [15-18].

Like the present study, Almeida-Montes et al. reported that lower HDL-C was related to depression in a five-year cohort study [11]. Melin et al. also reported the same findings [30]. Against the present study's findings, the studies of Khalid et al. and Olusi et al. displayed higher HDL-C concentrations in Major depressive disorder patients $[29,31]$.

Comparing the total serum cholesterol of the case and control group, we could not find any statistical difference; however other researchers reported a significant relationship between low serum cholesterol [5, 7, 10,13,19,32] or high serum cholesterol [9] and mental disorders such as depression and suicide attempts. Like this study, some studies did not indicate any significant relationship between total serum cholesterol and depression [10,15, 16,18]. Gupta et al. reported that low HDL and high LDL might be protective against depression but did not report any statistical difference between the total cholesterol in depressed and non-depressed groups [33]. Almeida et al. indicated that the serum levels of serotonin were significantly lower in patients with depression who had a recent suicidal attempt than in those who had
Hashemi Mohammad-Abad N. et al.

not [18]. Terao et al. showed the serum cholesterol levels might be positively associated with serotonin function; low serum levels of serotonin may increase the risk of suicidal attempts in individuals with low cholesterol [19]. However, there was no significant difference between the case and control groups in this research in terms of serotonin.

Larger studies with larger sample sizes and implementing experimental and trial studies for more confident conclusions are suggested.

\section{Conclusion}

The serum HDL-C concentration of depressed patients is lower than normal people, and the serum LDL-C concentration of depressed patients is higher than normal people.

Acknowledgments: The authors thank all the participants along with their families. We are also grateful to our colleagues in Shahid Mofatteh Psychiatric Clinic, Rajaee Hospital, and the vice chancellor for research, Yasuj University of Medical Sciences, to assist this study.

Ethical Permissions: The ethics committee and vice chancellor for research at Yasuj University of Medical Sciences approved the study.

Conflicts of Interests: None declared by Authors.

Authors' Contribution: Hashemi Mohammadabad N. (First author), Introduction author/Original researcher/Discussion author (350\%); Hoseiniyan L. (Second author), Introduction author/Assistant researcher/Discussion author (30\%); Malekzadeh J. (Third author), Assistant researcher/Methodologist/Statistical analyst/Discussion author (35\%).

Funding/Sources: There was no funding.

\section{References}

1- Kaelber CT, Moul DE. Epidemiology of depression. New York: Guilford Press; 1995.

2- Kessler RC, Berglund P, Demler O, Jin R, Koretz D, Merikangas KR, et al. The epidemiology of major depressive disorder: Results from the national comorbidity survey replication (NCS-R). JAMA. 2003;289(23):3095-105.

3- Williams DR, Gonzalez HM, Neighbors H, Nesse R, Abelson JM, Sweetman J, et al. prevalence and distribution of major depressive disorder in African Americans, Caribbean blacks, and non-Hispanic whites: Results from the national survey of American life. Arch Gen Psychiatry. 2007;64(3):305-15.

4- Boston PF, Dursun SM, Reveley MA. Cholesterol and mental disorder. Br J Psychiatry. 1996;169(6):682-9.

5- Partonen T, Haukka J, Virtamo J, Taylor PR, Lonnqvist J. Association of low total serum cholesterol with major depression and suicide. Br J Psychiatry. 1999;175:259-62. 6- Sadock BJ, Sadock VA. Kaplan and Sadock's synopsis of psychiatry: Behavioral sciences/clinical psychiatry. Philadelphia: Lippincott Williams \& Wilkins; 2007.

7- Atmaca M, Kuloglu M, Tezcan E, Ustundag B. Serum leptin and cholesterol values in violent and non-violent suicide attempters. Psychiatry Res. 2008;158(1):87-91.

8- Wagner CJ, Musenbichler C, Bohm L, Farber K, Fischer AI, Von Nippold F, et al. LDL cholesterol relates to depression, its severity, and the prospective course. Prog Neuropsychopharmacol Biol Psychiatry. 2019;92:405-11. 
Relationship of Serum Lipid Profiles and Serotonin ...

9- Brunner J, Bronisch T, Pfister H, Jacobi F, Hofler M, Wittchen HU. High cholesterol, triglycerides, and bodymass index in suicide attempters. Arch Suicide Res. 2006;10(1):1-9.

10- Tedders SH, Fokong KD, McKenzie LE, Wesley C, Yu L, Zhang J. Low cholesterol is associated with depression among U.S. household population. J Affect Disord. 2011;135(1):115-21.

11- Almeida OP, Yeap BB, Hankey GJ, Golledge J, Flicker L. HDL cholesterol and the risk of depression over 5 years. Mol Psychiatry. 2014;19(6):637-8.

12- Buoli M, Caldiroli L, Guenzani D, Carnevali GS, Cesari M, Turolo S, et al. Associations between cholesterol and fatty acid profile on the severity of depression in older persons with non-dialysis chronic kidney disease. J Ren Nutr. 2020;1051-2276(20):30233-8.

13- Vilibic M, Jukic V, Pandzic-Sakoman M, Bilic P, Milosevic M. Association between total serum cholesterol and depression, aggression, and suicidal ideations in war veterans with posttraumatic stress disorder: A crosssectional study. Croat Med J. 2014;55(5):520-9.

14- Han KT, Kim SJ. Are serum cholesterol levels associated with cognitive impairment and depression in elderly individuals without dementia: A retrospective cohort study in South Korea. Int J Geriatr Psychiatry. 2021;36(1):163-73.

15- Chen CC, Huang TL. Association of serum lipid profiles with depressive and anxiety disorders in menopausal women. Chang Gung Med J. 2006;29(3):325-30.

16- Deisenhammer EA, Kramer-Reinstadler K, Liensberger D, Kemmler G, Hinterhuber H, Fleischhacker WW. No evidence for an association between serum cholesterol and the course of depression and suicidality. Psychiatry Res. 2004;121(3):253-61.

17- Cepeda MS, Kern DM, Blacketer C, Drevets WC. Low levels of cholesterol and the cholesterol type are not associated with depression: Results of a cross-sectional NHANES study. J Clin Lipidol. 2020;14(4):515-21.

18- Almeida-Montes LG, Valles-Sanchez V, Moreno-Aguilar J, Chavez-Balderas RA, Garcia-Marin JA, Cortes Sotres JC, et al. relation of serum cholesterol, lipid, serotonin and tryptophan levels to severity of depression and to suicide attempts. J Psychiatry Neurosci. 2000;25(4):371-7.

19- Terao T, Nakamura J, Yoshimura R, Ohmori O, Takahashi N, Kojima H, et al. relationship between serum cholesterol levels and meta-chlorophenylpiperazineinduced cortisol responses in healthy men and women. Psychiatry Res. 2000;96(2):167-73.
20- Shrivastava S, Pucadyil TJ, Paila YD, Ganguly S, Chattopadhyay A. Chronic cholesterol depletion using statin impairs the function and dynamics of human serotonin(1A) receptors. Biochemistry. 2010;49(26):542635.

21- Machin D, Campbell MJ, Tan SB, Tan SH. Sample size tables for clinical studies. Hoboken: Wiley; 2009.

22- Ghassemzadeh H, Mojtabai R, Karamghadiri N, Ebrahimkhani N. Psychometric properties of a Persianlanguage version of the Beck depression inventory-second edition: BDI-II-Persian. Depress Anxiety. 2005;21(4):18592.

23- Rashedi V, Rezaei M, Foroughan M, Delbari A. Validity and reliability of the depression in old age scale (DIA-S) in Iranian older adults. Arch Gerontol Geriatr. 2016;66:193-7. 24- Beck AT, Steer RA, Carbin MG. Psychometric properties of the Beck depression inventory: Twenty-five years of evaluation. Clin Psychol Rev. 1988;8(1):77-100.

25- Stefan-Dabson K, Mohammadkhani P. Psychometrics Characteristic of Beck Depression Inventory-II in Patients with major depressive disorder. Rehabilitation. 2007;8(29):80-6. [Persian]

26- Sharp R. The Hamilton rating scale for depression. Occup Med. 2015;65(4):340.

27- Rahimi C. Application of the Beck Depression Inventory-II in Iranian university students. Clin Psychol Person. 2014;12(1):173-88

28- Gharaei B, Mehryar M, Mehrabi F. Attribution style in patients with anxiety and depression comorbidity. Iran J Psychiatr Clin Psychol. 2000;5(4):99.

29- Khalid A, Lal N, Trivedi JK, Dalal PK, Asthana OP, Srivastava JS, et al. Serum lipids: New biological markers in depression?. Indian J Psychiatry. 1998;40(3):217-23.

30- Melin EO, Thulesius HO, Hillman M, Svensson R, LandinOlsson M, Thunander M. Lower HDL-cholesterol, a known marker of cardiovascular risk, was associated with depression in type 1 diabetes: A cross sectional study. Lipids Health Dis. 2019;18(1):65.

31- Olusi SO, Fido AA. Serum lipid concentrations in patients with major depressive disorder. Biol Psychiatry. 1996;40(11):1128-31.

32- Kunugi H, Takei N, Aoki H, Nanko S. Low serum cholesterol in suicide attempters. Biol Psychiatry. 1997;41(2):196-200.

33- Gupta R, Kumar Solanki R, Dubey V, Kumar Midha P, Pathak V. Association of lipid profile with depressive features in young hypertensives. J Pak Psychiatr Soc. 2008;5(2):101. 